ISSN: 2362-1303 (Paper) | eISSN: 2362-1311(Online)

JOURNAL OF ADVANCED ACADEMIC RESEARCH (JAAR)

January 2015

\title{
Application of Structural-Functional Theory in Risk of HIV Transmission
}

Tej Bahadur Karki ${ }^{1}$ \&Prof. Dr. Ritu Prasad Gartoulla ${ }^{2}$

${ }^{1}$ PhD Scholar, Dr. K. N. Modi University, Newai, Rajasthan, India

${ }^{2}$ Medical Anthropologist, Institute of Medicine, Maharajgunj, Kathmandu, Nepal

Corresponding Author

Tej Bahadur Karki

Email: fpantej.karki@gmail.com

\section{Abstract}

The study was conducted with the purpose to explore the interrelationship and interdependency between the individual and whole social systems that effects on HIV transmission during the time

of social changes and transformation. The concept of structural functional theory was adopted to conduct this study. Phenomenological approach was applied to explore the experiences of risk behavior of human immune deficiency virus (HIV) transmission among the respondents working in Kathmandu valley (Kathmandu, Lalitpur and Bhaktpur districts). This Research was based on exploratory research design and simple random technique was used to select the respondents. The Study was conducted in Kathmandu valley among garment factory workers, brick factory workers, transport workers and health workers. Individual factors, socio-cultural factors, economic factors, educational factors and political factors are found as a functional unit of society which functions to influence the risk of HIV transmission in whole social structure. So, the finding is individual should be aware on the negative function of factors which can influence to increase the risk of HIV transmission. Cultural practices should be open to discuss about the risk behavior of people regarding their connection with HIV transmission.

Keywords: HIV Transmission, Risk, Structural-functional, Theory

\section{Introduction}

Structural Functionalism is a sociological theory that attempts to explain why society functions the way it does by focusing on the relationships between the various social institutions that makes up society (e.g., government, law, education, religion, etc). According to the Woodger, 1948, Merton, 1968, Structural functionalism has a lengthy history in both the biological sciences and the social sciences. Functionalism's history goes back to Aristotle's study of ultimate causes in nature or of actions in relation to their ends, or utility. Developed in $17^{\text {th }}$ century France, Montesquieu's doctrine of separation of powers is based on the notion of functions that are best undertaken separate from each other as a means of ensuring stability and security (Fisher, 2010).Structural functional, especially in the work of Talcott Parsons, Robert Merton, and their students and followers, was for many years the dominant sociological theory (Ritzer, 2011). 
ISSN: 2362-1303 (Paper) | eISSN: 2362-1311(Online)

JOURNAL OF ADVANCED ACADEMIC RESEARCH (JAAR)

Functionalists tend to view social and political units in more holistic, organic terms. Susser said "Social practices are said to have a functional role in sustaining the system as a whole" (1992, p. 204).Functionalism became important when Darwin's evolutionary theories began to influence thinking about human behaviour Darwin conceived of the idea of survival in functional terms. Each function was important to the survival of the whole system.Francesca M. Cancian (19ó8) describes two distinctive types of functional analysis: traditional and formal.Traditional functional analysis is the most commonly used. It is based on the premise that all social patternswork to maintain the integration and adaptation of the larger system. Formal functional analysis is called formal because itdoes not include a theoretical orientation or a substantivehypothesis about events. Rather it examines the relationshipsbetween elements. It contrasts with the traditionaltype of analysis in that its proponents reject the attributesof "integration" and "adaptation" in favour of an examinationof the equilibrating or feedback functions in systems (Fisher, 2010).

The general diagram of structural Functionalism is used as bellow:

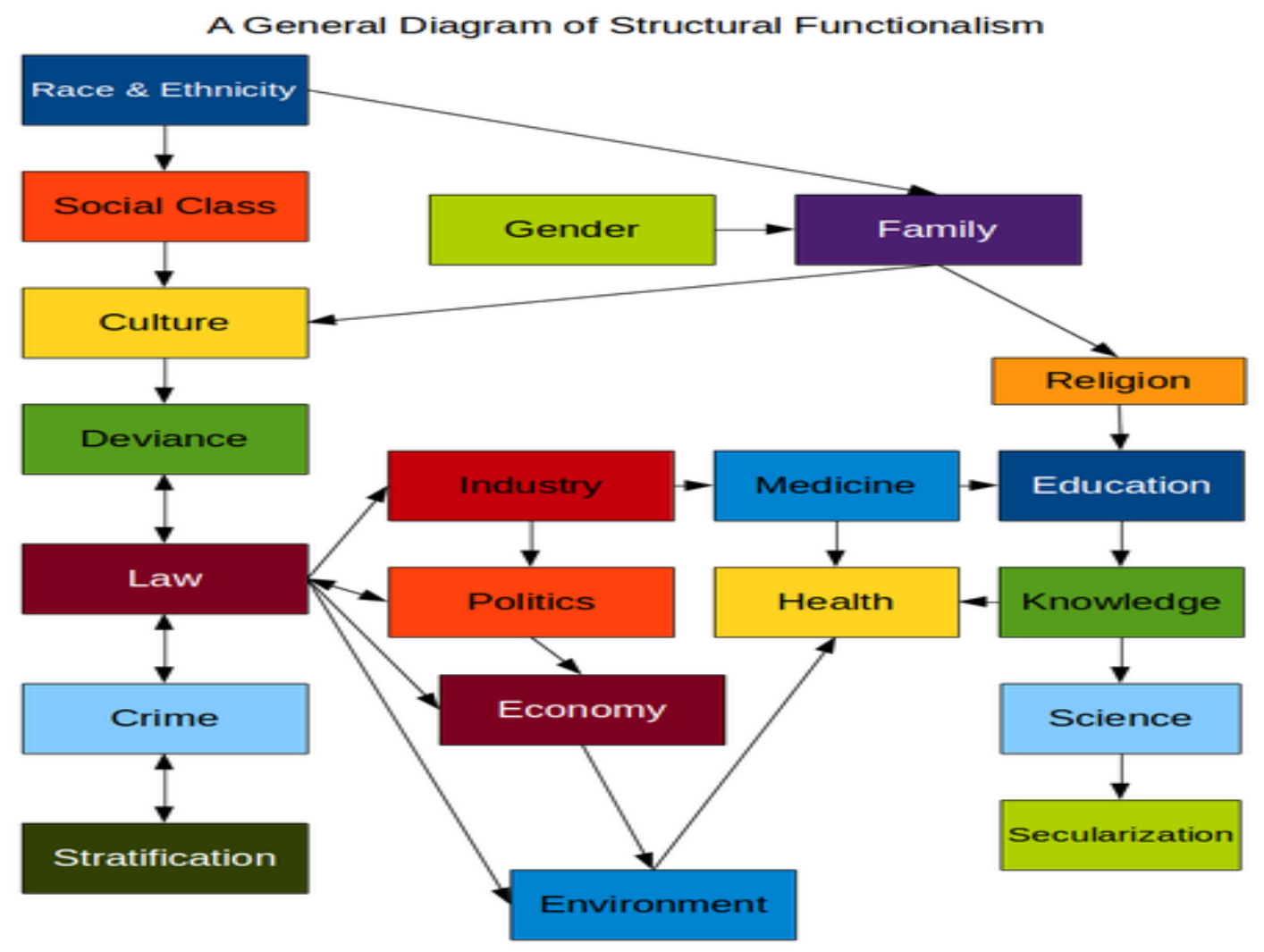

Sources: (WIKIBOOKS, 2014) 
ISSN: 2362-1303 (Paper) | eISSN: 2362-1311(Online)

JOURNAL OF ADVANCED ACADEMIC RESEARCH (JAAR)

January 2015

Talcott Parsons is one of the Grand Old Men of world of sociology. Regarding the structural functionalism of Parsons, he talks about the structure of general Action systems which covers the cultural system, social system, behavioral organism and personality system. In social system, he also talks about the relationship between the actors and social system (Ritzer, 2011). On the one hand, actor has primary role to develop the social system. On the other hand, social system controls the function of actor. During the course of life cycle of one individual, people play the various roles and do the practices. Regarding the risk behavior; willingly or unwillingly people engage in risk taking behavior which creates the problem in life. In connection with this point of Parsons, the main focus of this study is to explore the interrelationship and interdependency between the individual and whole social systems and their effects on HIV transmission during the time of social changes and transformation. The broader research question of this study is that how interaction between the individual and social systems plays the roles to increase the risk of HIV transmission?

\section{Method}

The study was conducted among the 404 transport workers, brick factory workers, health workers and garment factory workers working in Kathmandu valley (Kathmandu, Lalitpur and Bhaktpur districts) by using the self-administered structured questionnaires. Besides that, 22 indepth interview and 5 case studies were collected. Concurrent mixed design was adopted to collect and analyse the data. Phenomenological approach was applied to collect the human experience in their phenomena and how people understand the risk behaviour of HIV transmission and how various social factors associate with individual behaviour of people. The findings of primary data was compared and discussed with secondary data. Random sampling was done to select the respondents. The study was conducted in 2013.

\section{Result and Discussion}

The study has identified the interaction between the different factors and social systems which affect in increasing the risk of HIV transmission in society as extraneous factors. Researcher found that there is direct relation between the individual factors; knowledge and attitude towards HIV and practices related with sexual behavior and there is indirect relationship found between other factors (e.g. socio-cultural, educational, economic and political) and risk of HIV transmission.

Out of total 404 respondents, $29.46 \%$ were females and rests were males. Among them, 57\% respondents were married and rest was unmarried. As per ethnicity $53.2 \%$ of respondents were Janjati (ethnic group) followed by 30.44\% Chhetri and Brahmin, 11.38\% Dalit and 5\% Muslim/Yadav were participated in research. The mean age of the respondents was 27.31 years and Std. Deviation was 7.614, which ranges from 15 years to 49 years. As data of education level of respondents shows that majority $(25.50 \%)$ of respondents had primary level of education 
ISSN: 2362-1303 (Paper) | eISSN: 2362-1311(Online)

JOURNAL OF ADVANCED ACADEMIC RESEARCH (JAAR)

followed by $27.48 \%$ respondents from the Higher secondary level and above, $21.29 \%$ from lower secondary level, $13.12 \%$ from secondary level, $7.92 \%$ from literate and $4.7 \%$ were illiterate respondents.

The following pictorial diagram shows the interrelationship of the different functional units in society and its effect on risk of HIV transmission.

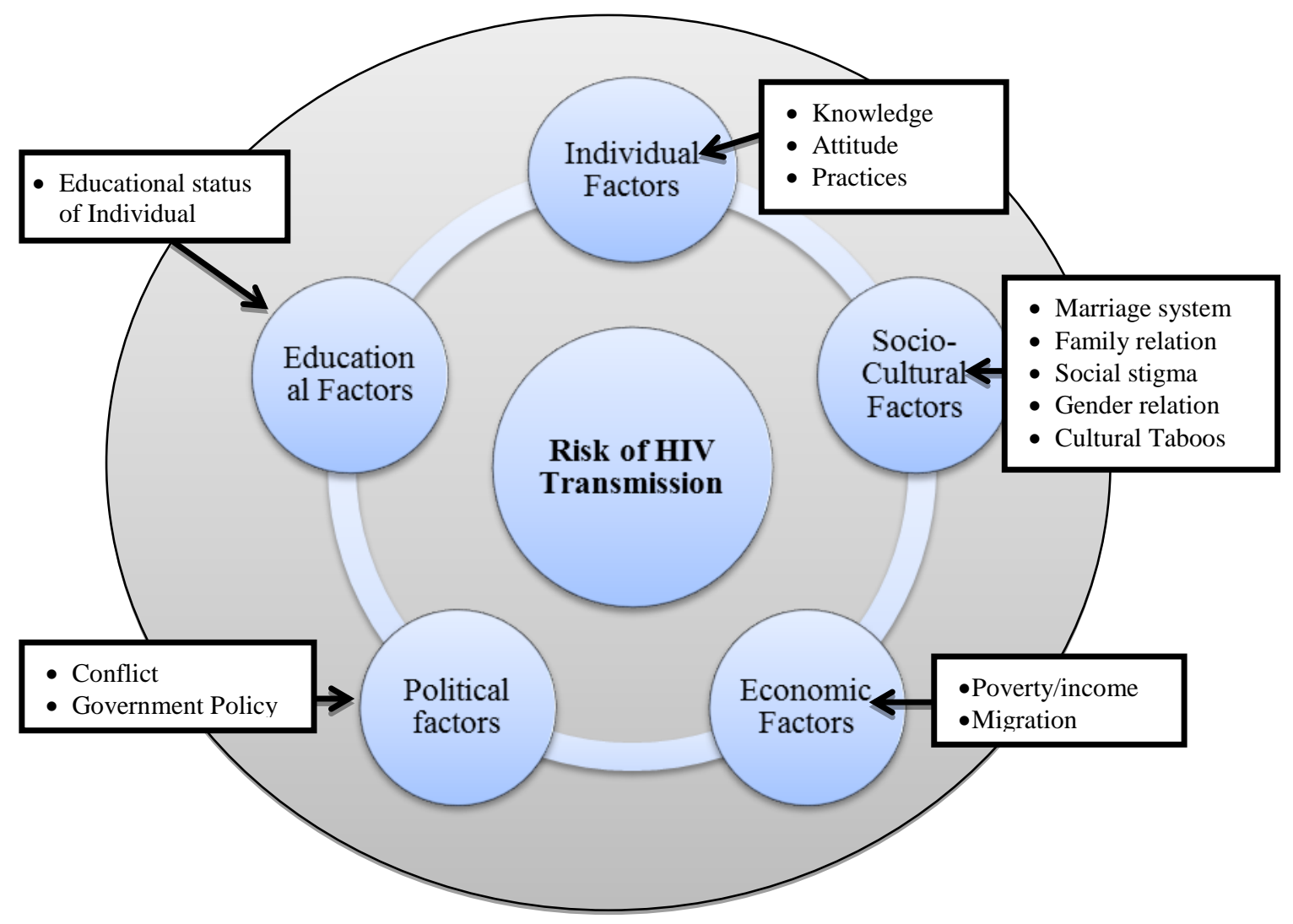

Figure 1: Structural-Functional Theory of Risk of HIV Transmission

The terms functional analysis and structural analysis both have been applied to a great variety of approaches in many disciplines. According to Susses, the functional approach is used more often than any other method in the study of Western political science (Susser, 1992). Structural functional theory is one of the broader approaches which can be used to explain the functional relation of different units of society and its effect on change and development of society. Researcher has adopted the lens of this theory to explore the functional relationship of different factors of society to influence the changing scenarios of HIV and AIDS.

In course of this study, it was also observed that in some cases, cultural factors of Nepalese society had direct contribution increasing the risk of HIV transmission. Cultural practices are different in different geographical location. Some closed society has rigid types of cultural 
ISSN: 2362-1303 (Paper) | eISSN: 2362-1311(Online)

JOURNAL OF ADVANCED ACADEMIC RESEARCH (JAAR)

January 2015

taboos on discussion of sexual behavior which is contributing in HIV transmission. A wife cannot ask to husband about their sexual behavior as well as husband cannot ask to wife about her sexual interest. Culturally, people become used to the blind trust on sex partners. They have to adjust anyhow in their own cultural because culture affects the personality. According to the Rao, man is not only a social animal but also a cultural being. Man's social life has been made possible because of culture. Cultural is something that has elevated him from the level of animal to the heights of man. Man cannot survive as man without culture. It represents the entire achievements of mankind (Rao, 2008).

"My husband became the HIV positive due to lack of awareness on HIV and AIDS, there may be negligence also. On the other hand, my blind trust towards my husband made me also HIV positive."

- 28 years married HIV Positive Female

"Being a HIV positive is shameful work. So, if my family members or I would be infected then I could not disclose HIV status in communities".

- Brick factory worker, 32 years married male

Economic factors have also significant role for the increasing risk of HIV transmission. In the Nepalese case, migration is one of the main causes of inadequate opportunity of employment in own country. Actually, the roots cause of migration is poverty. Poverty is explained as a social problem (Heald, 2010, p. 140). According to the report of National Health Committee of New Zealand, poverty can be defined in absolute or relative terms. Poverty has long been recognized as an important determinant of ill health. People who are poor have worse self-reported health, higher rates of disability, and higher rates of death, disease and injury. Children from poor families have higher rates of illness, injury and death than other children (June 1998, p. 24). To explain the basic causes of poverty, sociologists are increasingly focusing their attention on society as a whole and particularly on the stratification system, rather than studying the poor in isolation. As Peter Townsend states, 'The description, analysis and explanation of poverty in any country must proceed within the context of a general theory of stratification'. Theories of stratification should provide theories of poverty since the poor are part of stratification systemsthe bottom part (Heald, 2010, pp. 160-161). In connection between the poverty and HIV transmission, UNAIDS has reported that 'Poverty is also seen as enhancing vulnerability to HIV. The growing rates of HIV and AIDS in economically disadvantaged communities of the industrialized world and in developing countries emphasize the role played by poverty in fuelling the epidemic. There has long been worldwide recognition of the negative impact of poverty on health and of the need to undertake aggressive action towards poverty alleviation and development' (UNAIDS, 1998, p. 8). 
ISSN: 2362-1303 (Paper) | eISSN: 2362-1311(Online)

JOURNAL OF ADVANCED ACADEMIC RESEARCH (JAAR)

January 2015

Similarly, we can observe the close relationship between the political factors and risk of HIV transmission because politics can determine the quality and effectiveness of policy of concerned government. Nepal Government has developed next 5 years (2011-2016) National HIV and AIDS strategy following the 2006-2011 strategy. As stated in introduction of strategy, building on the achievements, lessons and experiences of the past five years, the strategy (2011-2016) will focus on the following key points:

- Addressing the all dimensions of continuum of care from prevention to treatment care and support

- Effective coverage of quality interventions based on the epidemic situation and geographical prioritization

- Health system and community system strengthening

- Integration of HIV services into public health system in a balanced way to meet the specific needs of target populations

- Strong accountability framework with robust HIV surveillance, program monitoring and evaluation to reflect the results into NHSP-II and National Plan. (National Centre for AIDS and STD Control, November 2011)

"I can't blame society in increasing the risk of HIV. Government should be more careful about the treatment and job opportunities of people living with HIV (PLHIV)."

-29 years married HIV Positive male

In the perceptual data collected from the respondents shows that there is significant association between the conflict and risk of HIV transmission but analysis of secondary data of HIV prevalence generated by Nepal Government shows that there is similar trend of up and down ratio of HIV prevalence in pre-conflict, during conflict and post-conflict period of Nepal in last 20 years.

Education is one of the key factors which determine the personality of people. The study found that education has vital role to increase the risk of HIV transmission. There is significant association found among the response of different target groups regarding the influence of education on risk behaviour of people.

'In transport sectors, more time people live out of home and want to do romance so when they use to take drink then they desire sex. Comparatively now a days some educated people are also involved in transport sectors. Somehow they are aware about the HIV transmission. Education is major factor which is associated with risk taking behaviour. Those people who have good education they are definitely aware about the HIV transmission.' 
ISSN: 2362-1303 (Paper) | eISSN: 2362-1311(Online)

JOURNAL OF ADVANCED ACADEMIC RESEARCH (JAAR)

January 2015

- $\quad$ Transport workers (36 years, Mr. KC, resident of Kaski district (Western Region of Nepal).

The commutative effect of all these factors goes in individual factors because personality is affected by the whole cultural phenomena of society. How one people grow, observe the phenomena, got knowledge, develop their attitude and do the practices are depend on the structural function of social variables. In this study, researcher try to divide the individual factors into three main variables i.e. knowledge, attitude and practices. The observation found that around $95 \%$ people have knowledge of HIV transmission, only around $41 \%$ are ready to disclose their HIV status in society and only around $25 \%$ has practices to use the condom in their $1^{\text {st }}$ sexual contact. Risk of HIV transmission can be reduced only by safer practices but it is found very weak. Various socio-cultural factors are responsible to determine the good practices in any movement.

"when attachment becomes closer with any sex partner and both will be ready for sexual intercourse, everything forgets at that time, when \& how HIV transmits, and none cares either it transmits or not".

- Brick Factory worker (26 years resident of Salyan district)

\section{Conclusion}

People existence can only be meaningful when they interact with their phenomena. Personality cannot be developed in isolation so it is natural and mandatory that social variables should functional together to change the social structure. We can observe the positive and negative both types of influence of functional units in social change. HIV is one of social problem; it is acquired disease so it can be prevented by using the social treatment theory. Community and individual should be aware on the function of social variables which can directly or indirectly influence risk behaviour of HIV transmission. HIV can only be transmitted when individual behaviour will be wrong in practices. Cultural practices are one of the key drivers of personality development; but culture is manmade so individual can change the cultural practices if it becomes problematic for individual life. E.g. we have to convince for open discussion on sexual practices in our close society also which can give the broader knowledge of sexual transmitted infections. So, in researcher come to the conclusion that risk of HIV transmission should be observed from the holistic perspective of social structure. 
ISSN: 2362-1303 (Paper) | eISSN: 2362-1311(Online)

JOURNAL OF ADVANCED ACADEMIC RESEARCH (JAAR)

January 2015

\section{References}

Fisher, J. R. (2010). System Theory and Structural Functionalism. In J. T. Breuning (Ed.), 21st Century Political Science: A Reference Handbook (Vol. 1, pp. 71-80). Loss Angeles, London, New-Delhi, Singapore, Washington DC: Sage \& Reference.

Heald, M. H. (2010). Sociology : Themes and Perspectives. New Delhi, India: OXFORD University Press.

National Centre for AIDS and STD Control. (November 2011). NATIONAL HIV/AIDS STRATEGY 2011 - 2016. Teku, Kathmandu, Nepal: Government of Nepal: Ministry of Health and Population.

National Health Committee . (June 1998). The Social, Cultural and Economic Determinants of Health in New Zealand: Action to Improve Health. New Zealand: National Advisory Committee on Health and Disability.

Rao, C. N. (2008). Sociology: principles of sociology with an Introduction to Social Thought. Ram Nagar, New Delhi: S. Chand \& Company Ltd.

Ritzer, G. (2011). Sociological Theory (5th Edition). India: Tata McGraw-Hill.

Susser, B. (1992). Apptooches to the stdy of polit;cs. New York: Macmillan.

UNAIDS. (1998). Expanding the global response to HIV/AIDS through focused action Reducing risk and vulnerability: definitions, rationale and pathways. Geneva 27 - Switzerland: Joint United Nations Programme on HIV/AIDS.

WIKIBOOKS. ( 2014, April 2). Retrieved May 13, 2014, from WIKIBOOKS: Open Books for an open world: http://en.wikibooks.org/wiki/Sociological_Theory/Structural_Functionalism 